\title{
Germination Ecology of Arundinaria alpina (K. Schum.) and Oxytenanthera abyssinica (A. Rich.) Munro Seeds: Indigenous Bamboo Species in Ethiopia
}

\author{
Tinsae Bahru, ${ }^{1}$ Yigardu Mulatu, ${ }^{2}$ and Berhane Kidane ${ }^{2}$ \\ ${ }^{1}$ Central Ethiopia Environment and Forest Research Center (CEE-FRC), Addis Ababa, Ethiopia \\ ${ }^{2}$ Ethiopian Environment and Forest Research Institute (EEFRI), Addis Ababa, Ethiopia \\ Correspondence should be addressed to Tinsae Bahru; batinsae@gmail.com
}

Received 11 July 2015; Accepted 15 September 2015

Academic Editor: Alexandre Sebbenn

Copyright (C) 2015 Tinsae Bahru et al. This is an open access article distributed under the Creative Commons Attribution License, which permits unrestricted use, distribution, and reproduction in any medium, provided the original work is properly cited.

Highland bamboo (Arundinaria alpina) and lowland bamboo (Oxytenanthera abyssinica) are indigenous to Ethiopia and endemic to Africa. Seeds of A. alpina were collected from Dawa Wereda (District), while O. abyssinica seeds were collected from Pawe and Sherkole Weredas. In this study, seed presowing treatments, effects of dry heat, moist heat, and light/dark treatments on the germination of seeds were tested. The averages were of 59,416 and 8,393 seeds contained within $1 \mathrm{~kg}$ of A. alpina and O. abyssinica seeds within 86 and 91\% pure seeds, respectively. From $1 \mathrm{~kg}$ of pure seeds 37,301 and 7,168 seedlings are raised in the laboratory in their respective orders. The result revealed that control seeds of A. alpina and O. abyssinica showed the best germination of 73 and $98 \%$. Germination of both dry and moist heat treatments of $O$. abyssinica seeds was significantly improved at 60 and $80^{\circ} \mathrm{C}$. Unlike A. alpina seeds, seeds of $O$. abyssinica had better germination for light treatment compared to dark. For effective large scale plantation and raising of A. alpina and O. abyssinica seedlings from its seeds for laboratory, control seeds supply to necessary light source (for O. abyssinica seeds) is recommended.

\section{Introduction}

There are two indigenous species of bamboo in Ethiopia: the highland bamboo (Arundinaria alpina (K. Schum.)) and lowland bamboo (Oxytenanthera abyssinica (A. Rich.) Munro) $[1,2]$. These species are indigenous to Ethiopia and endemic to Africa [2]. The species of bamboo are classified under the member of grass family known as Poaceae [1]. Arundinaria alpina is commonly known by various local names including QERKEHA in Amharic; LEMEN in Afan Oromo; ARKAY in Tigrinya; SHIKATO/SHINATO in Kefinya; and WEYSHA in Welaytinya/Gamonya $[1,3]$. It is a hollow clump forming bamboo growing up to a height of $15 \mathrm{~m}$ and a diameter of $12 \mathrm{~cm}$ from a stout branching rhizome [1]. Arundinaria alpina is found in montane forest often on volcanic soils and forming extensive pure stands. In addition, A. alpina occurs with Podocarpus in upland rainforest and with Juniperus in drier forest frequently planted along roads and in villages. It is widely distributed in Cameroon Mountain, Zaire (Kivu),
Rwanda, Burundi, Sudan (Imatong mountains), the east African mountains, and Malawi. In Ethiopia A. alpina is found in Gojam, Shewa, Kefa, Gamo Gofa, Sidamo, and Bale Regions at the altitudes ranging from 2,200 to $4,000 \mathrm{~m}$ above sea level [1].

Similarly, O. abyssinica is commonly known by various local names in different areas with respect to their languages. Accordingly, it is known as SHIMEL in Amharic; ARKAY in Tigrinya; and SHIMALA in Welaytinya or Afan Oromo $[1,4,5]$. Oxytenanthera abyssinica is a solid woody clump forming bamboo growing up to a height of $3-13 \mathrm{~m}$ and a diameter of $5-10 \mathrm{~cm}$ [1]. It is widely distributed in eastern and southern Africa mainly Ethiopia, Malawi, Zimbabwe, and Zambia $[5,6]$, while in western Africa, it is located in some parts of Ghana and Senegal. The species is widely distributed in lowland regions of western and northwestern parts of Ethiopia [6] in Tigray, Gonder, Gojam, and Welega Regions [1]. Oxytenanthera abyssinica is found in Savanna woodland, favoring river valleys, often forming extensive stands at 
the altitudes ranging from 1,200 to $1,800 \mathrm{~m}$ above sea level [1]. Its annual rainfall is ranging from about 700 to $1,000 \mathrm{~mm}$, which is concentrated over a period of three to four months with the mean annual temperature of above $30^{\circ} \mathrm{C}$ [5]. The species is easily adaptable to poor soils and provided as a buffer zone for desert areas [5].

Bamboo resources in Ethiopia have a considerable potential to socioeconomic development of the local people; mitigation and adaptation of global climatic change through carbon sequestration; biodiversity conservation and wider ecological adaptation [1, 7-9]. However, little or almost no significant research and development attention are given to bamboo resources. Currently, the bamboo resources of Ethiopia are underutilized and have been neglected by development practitioners. For instance, their importance and use are limited to hut construction, fencing, production of handicrafts (basketry, mats, and decorative items), furniture, and other household utensils $[1,3-5,8]$. Due to this reason, there is indiscriminate resource depletion by various human activities and mass flowering and subsequent death of bamboo resources $[2,3,5,8,10]$. This, in turn, influences the sustainable use and management of the species and its genetic resource conservation. Furthermore, poor seed storage characteristics and hence low viability as well as limited availability of seeds and flowering at longer intervals are the practical problems in bamboo large-scale propagation using seeds $[3,5,11]$. Various sources reported that the species produces seeds, which is difficult to get, collect, and process. Lack of easy access to seeds and seedlings are in general associated with seed handling and storage problems, which further limit the use of the species in bamboo improvement, expansion, and conservation programmes. Therefore, to fill this research gap it is imperative to find appropriate ex situ conservation methods of bamboo genetic bases on the long- and shortterm bases. Genetic improvement and large scale plantation of bamboo seedlings are largely dependent upon quality and quantity of seeds. Seed quality, in turn, comprises both the physiological viability and vigour of the seeds and their genetic quality. The ability to produce vigorous and healthy seedlings in the field, which are well adapted to the field, is an essential complement to genetic improvement. Secondly, planted seedlings are intended to provide the necessary product or service due to its high viability and vigour of seeds [12]. Hence, studying the germination ecology (effect of presowing seed treatments, light, and seed storage time) of seeds helps to select rapidly and vigorously germinating seeds under favourable environmental conditions that are capable of producing vigorous seedlings in the field. Therefore, the present study aimed at investigating germination ecology of $A$. alpina and $O$. abyssinica seeds for proper ex situ conservation of its genetic base.

\section{Materials and Methods}

2.1. Seed Collection, Handling, and Processing. Seeds of A. alpina were collected from Dawa Wereda (District), Guji Zone, Oromia Regional State, Ethiopia, whereas O. abyssinica seeds were collected from Pawe especial Wereda, Metekel
Zone and Sherkole Wereda, Assosa Zone of BenishangulGumuz Regional State, Ethiopia. To ensure maximum genetic diversity, seeds were collected from selected clumps of bamboo stands at a distance of at least $100 \mathrm{~m}$ apart between them [13]. The collected fresh seeds were put into perforated plastic bags and safely transported to Central Ethiopia Environment and Forest Research Center (CEE-FRC), Ethiopian Environment and Forest Research Institute (EEFRI). Seeds which had been attacked by insects or decayed were excluded, extracted, and cleaned in CEE-FRC seed processing room following the procedures by FAO [12]. Finally, the seeds were placed in perforated plastic bags and stored in cold room at $+5^{\circ} \mathrm{C}$ until the experiment was started as also partially applied by C. C. Baskin and J. M. Baskin [14]. This enables us to maintain the viability of seeds and prevent from insect attack by reducing seed moisture $[12,15]$. Moreover, the rate of physiological changes of many seeds becomes slow down by storing them at low temperatures [14]. Various germination tests were started shortly after the collection of seeds, that is, within a week [14].

\subsection{Determination of Purity Analysis and Moisture Content of} Seeds. Moisture content and purity analysis of A. alpina and O. abyssinica seeds were determined in the laboratory following the methods by FAO [12]. To determine moisture content, two samples of $5 \mathrm{gm}$ seeds each were drawn from the total seed lot of each species before the determination of purity analysis. Samples were weighed and dried in an oven for 17 hours at $103^{\circ} \mathrm{C}$. Finally, samples were placed in a desiccator, cooled for 30 minutes, and then reweighed. The wet weight or fresh weight basis of moisture content was calculated as

$$
\begin{aligned}
& \text { Moisture content } \% \\
& =\frac{\text { Original weight }- \text { Oven dry weight }}{\text { Original weight }} \times 100 \text {. }
\end{aligned}
$$

Similarly, two samples of 35 gm seeds each were drawn from the total seed lot of each species containing all the impurities and weighed. Following this, the pure seed was removed and reweighed separately. The percentage of pure seed was determined as follows:

$$
\text { Purity } \%=\frac{\text { Weight of pure seed }}{\text { Total weight of original sample }} \times 100 \text {. }
$$

\subsection{Determination of Seed Size and Weight of A. alpina and O.} abyssinica Seeds. Seed weight of A. alpina and O. abyssinica was determined following FAO [12]. Accordingly, 8 replicates of 100 pure seeds each were randomly drawn from the total seed lot and expressed as weight of whole seeds. Hence, the 1000 pure seed weight was converted to number of pure seeds per kg:

$$
\text { Number of seeds per } \mathrm{kg}=\frac{1000 \times 1000}{\text { weight in } \mathrm{g} \text { of } 1000 \text { seeds }} \text {. }
$$

To measure the seed size of $A$. alpina and O. abyssinica seeds, 100 seeds in 4 replicates of 25 seeds each were randomly drawn from the total seed lot of each species. Following this, 
the seed length and seed width were measured in millimeters (mm) using seed caliper [16].

Finally, the number of seedlings raised per kg of seeds in the laboratory also was calculated as follows:

Number of seedlings raised per kg of seeds

$=$ Number of seeds per $\mathrm{kg}$

$\times$ percentage germination $\times$ percentage purity.

2.4. Presowing Seed Treatments. Effect of presowing seed treatments on the germination of A. alpina and O. abyssinica species was assessed by conducting different presowing seed treatments. Accordingly, whether pretreatment improves seed germination or not, $A$. alpina seeds were subjected to six treatments, which was decided by the first author based on the past experience on various seed tests (T1-T6): nicking the seeds at the opposite side of embryo or bottom part (T1); soaking the seeds in cold water $\left(19^{\circ} \mathrm{C}\right)$ for $6 \mathrm{hrs}(\mathrm{T} 2)$; soaking the seeds in cold water $\left(19^{\circ} \mathrm{C}\right)$ for $12 \mathrm{hrs}$ (T3); soaking the seeds in cold water $\left(19^{\circ} \mathrm{C}\right)$ for $24 \mathrm{hrs}$ (T4); seeds immersed in hot/boiling water $\left(100^{\circ} \mathrm{C}\right)$ for 1 minutes (T5); and control seeds (seeds without treatment or intact seeds) (T6).

Similarly, O. abyssinica seeds treated to five treatments (T1-T5): nicking the seeds at the top part where the embryo located (T1); nicking the seeds at the opposite side of embryo or bottom part (T2); soaking the seeds in cold water $\left(19^{\circ} \mathrm{C}\right)$ for $24 \mathrm{hrs}$ (T3); the seeds immersed in hot/boiling water $\left(100^{\circ} \mathrm{C}\right)$ for 5 minutes $(\mathrm{T} 4)$; and control seeds (seeds without treatment or intact seeds) (T5). To investigate the effect of nicking on germination of seeds, a small portion of the seed coat was carefully removed at the side or opposite of the hilum using the sharp edge of a Scissor until a small hole was remained. This allows imbibitions of water and oxygen by braking seed coat dormancy for some species [12, 17]. Great care was taken to avoid/not to damage seed embryo and the emerging radical as well.

2.5. Dry Heat Treatment. In this test, O. abyssinica seeds were treated with dry heat (seeds placed in glass bottle without water) in preheated dry oven at a range of different temperatures $\left(60,80\right.$, and $\left.100^{\circ} \mathrm{C}\right)$ and duration $(15,30$, and 60 minutes) for each range. The test had also a control (without heat treatment). This was applied following the method by Martin et al. [18], Teketay [19, 20], C. C. Baskin and J. M. Baskin [14], and Bahru et al. [17].

2.6. Moist Heat Treatment. Seeds of O. abyssinica were treated with moist heat in preheated dry oven at a range of different temperatures $\left(60,80\right.$, and $\left.100^{\circ} \mathrm{C}\right)$ and duration $(15,30$, and 60 minutes) for each range following the method by Bahru et al. [17]. Moist heat treatment is similar to dry heat but the only difference is in moist heat seeds which were placed in glass bottle containing water and treated in dry oven. The test had also a control (without heat treatment).

2.7. Light/Dark Treatment. Effect of light or darkness on the germination of A. alpina and O. abyssinica seeds was tested by sowing seeds in light and under dark condition. Based on this, for both treatments control seeds were sowed and enclosed in Petri-dishes on moist filter paper. For dark treatment, Petri-dishes were immediately wrapped with aluminum foil to avoid exposure of seeds to light. For light treatment, Petridishes were exposed to light from florescent tubes, which are provided for the laboratory room. Finally, the Petri-dishes of both treatments were placed on a table at room temperature $\left(21 / 22^{\circ} \mathrm{C}\right)$. This was applied following the methods by Teketay $[19,20]$, C. C. Baskin and J. M. Baskin [14], and Bahru et al. [17].

2.8. Effect of Storage Time on Germination Capacity. To assess effect of storage time of $A$. alpina seeds on seed germination, seeds were stored for $0,180,300$, and 360 days at room temperature $\left(21 / 22^{\circ} \mathrm{C}\right)$ in cold room and the seed germination tests were carried out following the methods by Bahru et al. [21].

2.9. Daily Germination Assessment of Seeds. All germination tests were conducted in such a way that all treatments had 100 seeds in 4 replicates of 25 seeds each. The filter paper was kept moist with distilled water as much as possible throughout the entire experimental period. In order to moisten the filter paper, water was added until the paper was saturated. Following this, the Petri-dish was holding on its side to allow excess water drained from the filter paper [14]. Seeds were inspected everyday starting from the 2 nd day after sowing except those seeds incubated in the dark. All germinated seeds were counted and discarded daily in order to avoid the double counting of seeds. A seed was considered as germinated when the radicle was penetrated out from the seed coat and clearly appeared visually. The daily germination count was continued until no more seeds had been germinated, that is, 28 germination days. This method was applied following C. C. Baskin and J. M. Baskin [14] and Bahru et al. [17, 21].

Statistical Data Analysis. Germination percentage data were first arcsine transformed before statistical analysis to fulfill the normality assumption [14, 22]. Germination capacity (GC) and coefficient of rate of germination (CRG) or coefficient of velocity were determined following the method adopted by Hartmann and Kester [15] and Mamo et al. [16]. Germination capacity is the proportion of total number of germinated seeds to that of sown seeds and expressed as in percentage. Coefficient of rate of germination also is calculated and expressed in percentage as follows:

$$
\mathrm{CRG}=\left[\frac{\sum n}{\sum(t \times n)}\right] \times 100,
$$

where $n$ is the number of seeds completing germination on day $t$ and $t$ is the time in days starting from day 0 , the day of sowing.

Mean daily germination or daily germination speed (DGS) was calculated as the cumulative germination percentage at the end of the test divided by the number of days from sowing to the end of the test.

Germination energy (GE) was measured based on the energy period lasting until daily germination falls to less than 
TABLE 1: Determination of purity analysis, moisture content, seed weight, and seed characterisation of A. alpina and O. abyssinica species.

\begin{tabular}{lcccccccr}
\hline BS & BP & PP & MC & SK & GP & SW & SL & SW \\
\hline A. alpina & Dawa & $86 \%$ & $6.9-8 \%$ & 59,416 & 73 & 17 & $0.59 \pm 0.09$ & $0.17 \pm 0.05$ \\
\hline \multirow{2}{*}{ O. abyssinica } & Pawe & $78 \%$ & $4-7 \%$ & 8,393 & 98 & 119 & $1.60 \pm 0.18$ & $0.30 \pm 0.06$ \\
& Sherkole & $91 \%$ & $4-6.9 \%$ & 8,121 & 97 & 123 & $1.60 \pm 0.18$ & $0.30 \pm 0.06$ \\
\hline
\end{tabular}

BS: bamboo species, GP: germination percentage, MC: moisture content, SW: 1000 seed weight (g), BP: provenance (locality), PP: purity percentage, SL: seed length (mm), SK: seeds per kg, and SW: seed width (mm).

$25 \%$ of the peak germination so as to include germinable seeds. It was measured following the method applied by FAO [12]:

$$
\mathrm{GE}=\left(\frac{\sum \mathrm{DGT}}{n}\right) \times 100,
$$

where GE is germination energy, DGT is daily germination total, $\Sigma D G T$ is the total obtained by adding DGT figure obtained from the daily counts, and $n$ is total number of sowed seeds.

Germination value $(\mathrm{GV})$ is expressed as total germination at the end of the test period with germination energy or speed of germination. It was calculated following the method adopted by FAO [12]:

$$
\mathrm{GV}=\left(\frac{\sum \mathrm{DGS}}{N}\right) \times\left(\frac{\mathrm{GP}}{10}\right),
$$

where $\mathrm{GV}$ is germination value, GP is germination percent at the end of the test, DGS is daily germination speed, $\Sigma D G S$ is the total obtained by adding every DGS figure obtained from the daily counts, and $N$ is the number of daily counts, starting from the date of first germination.

Data were analysed and evaluated by using descriptive statistics such as percentages, tables, graphs, and figures. In addition, the generalized linear model (GLM) was employed for the analysis of dry heat and moist heat data using SPSS Version 20.0 Computer Software Programme, whereas all the remaining data were determined by one-way analysis of variance (ANOVA) test at $95 \%$ or $99.9 \%$ confidence interval to test the statistical significance difference. Multiple comparison of Least Significance Difference (LSD) was also applied to show significance difference among the treatments.

\section{Results and Discussion}

3.1. Determination of Purity Analysis and Moisture Content. Purity analysis of $A$. alpina seeds indicated that its percentage was $86 \%$ (Table 1). Similarly, purity analysis of $O$. abyssinica seeds indicated that Sherkole provenance (91\%) had better purity analysis than Pawe provenance (78\%). Hence, the seeds are said to be pure seeds. Purity analysis of a given seed sample is the first test to be conducted so as to identify mature, pure, and germinating seeds for subsequent tests [12]. FAO [12] explained that moisture content has an impact on longevity of seeds in storage. Therefore, it is very important to check the amount of moisture in a given sample during storage.

On the other hand, the percentage moisture content from the average of the two samples of A. alpina and O. abyssinica seeds was found to be $6.9-8 \%$ and $4-6.9 \%$, respectively, for storage in cold room at room temperature $\left(21 / 22^{\circ} \mathrm{C}\right)$. Hartmann and Kester [15] reported that the most important storage conditions that maintain seed viability are low moisture content and low storage temperature. Hence, for seeds not adversely affected by low moisture conditions, each $1 \%$ decrease in seed moisture (between 5 and 14\% range) doubles the lifespan of the seed [15]. This is because various storage problems arise with increasing seed moisture including insect and fungal attack, stimulating germination and heating effect. Overall, in desiccation tolerant seeds, 4 to $6 \%$ moisture content is favourable for prolonged seed storage [15].

\subsection{Determination of Seed Weight and Size of A. alpina and} O. abyssinica Seeds. The overall seed weight test after purity analysis indicated that there were 59,416 seeds contained within one kilogram $(\mathrm{kg})$ of pure A. alpina seeds (Table 1). This, in turn, has a mean thousand seed weight of $17 \mathrm{~g}$. Therefore, from one $\mathrm{kg}$ of pure A. alpina seeds 37,301 seedlings are raised in the laboratory. Similarly, there were 8,393 and 8,121 seeds contained within $1 \mathrm{~kg}$ of pure $O$. abyssinica seeds in Pawe and Sherkole provenances, respectively. This, in turn, has a mean thousand seed weight of $119-123 \mathrm{~g}$. The results showed significant variation in seed weight from the two seed sources. Therefore, from $1 \mathrm{~kg}$ of pure O. abyssinica seeds 6,416 and 7,168 seedlings are raised in the laboratory in their respective orders.

On the other hand, $A$. alpina seed size reported that there were no significant differences $\left(F_{(0.05)}=0.556\right.$ and 0.813 , $\mathrm{df}=$ 3 , and $P=0.646$ and 0.490$)$ among the replications of seed length and width, respectively. The mean values were $0.59 \pm$ $0.09 \mathrm{~mm}$ and $0.17 \pm 0.05 \mathrm{~mm}$, in their respective orders. The lowest and maximum seed length were 0.40 and $0.80 \mathrm{~mm}$, respectively. The lowest and maximum seed width were also 0.1 and $0.2 \mathrm{~mm}$, respectively. Likewise, O. abyssinica seeds revealed no significant differences $\left(F_{(0.05)}=0.000\right.$, df $=1$, and $P=1.000$ ) between provenances in both seed length and width, respectively. Their mean values were $1.60 \pm 0.18 \mathrm{~mm}$ and $0.31 \pm 0.06 \mathrm{~mm}$, in their respective orders. The lowest and maximum seed length were 1.2 and $1.9 \mathrm{~mm}$, respectively. In turn, the lowest and maximum seed width were 0.2 and $0.4 \mathrm{~mm}$, respectively. Overall, FAO [12] and Ghosh and Singh [23] reported that heavy and larger seeds weigh more per seed than smaller seeds and hence contain more food reserves. Consequently, they are more likely to have higher germination percentage (Table 1) by providing more energy and produce initially more vigorous seedlings [12, 23]. Therefore, seed size and weight are important characters for selection of well-adapted and highly productive seed sources 


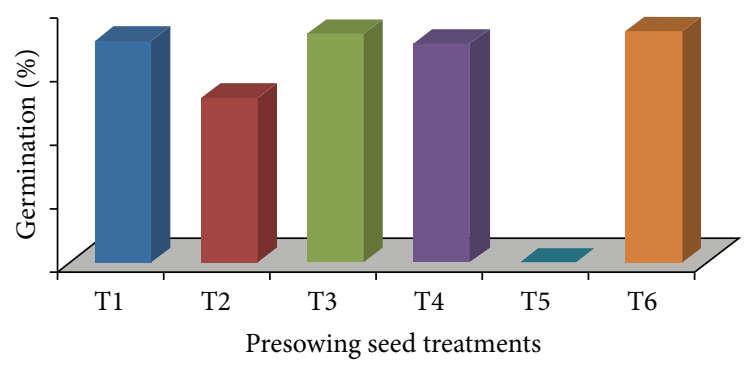

FIgURE 1: Presowing seed treatments of A. alpina seeds.

for silvicultural practices. As a result, this improves seedling productivity and reducing nursery cost through selection of quality seeds $[12,23]$.

3.3. Presowing Seed Treatment. Germination of A. alpina seeds recorded at the end of the experiment ranged between 0 and 73\% (Figure 1). Treatment 6 (T6) showed the best germination, which accounted $73 \%$. This was followed by T3 (72\%) and $\mathrm{T} 1(70 \%)$. On the other hand, T5 had the least germination $(0 \%)$. A decreased germination in hot or boiling water treatment is an indication of possibly damaged seed embryos [14].

Likewise, germination of $O$. abyssinica seeds among the different seed treatments ranged between 0 and $98 \%$ at $4-7 \%$ of moisture content stored in cold room $\left(+5^{\circ} \mathrm{C}\right)$ (Figure 2). Treatment 5 (T5) as well as T2 had the best germination (98\% each treatment), followed by T3 (94\%). For these treatments, germination was fastest, uniform, and completed within the 6 th and 7 th days after sowing. But, from the practical aspect sowing control seeds (T5) is more useful to save human power, time, and resource. This is due to the fact that treating seeds (e.g., acid or mechanical scarification using file, scalpel, and knife) is a very time-consuming and labour intensive method of making seeds permeable to water [14]. On the contrary, T4 scored $0 \%$ germination. Germination variation between T1 (28\%) and T2 (98\%) might indicated that nicking the seeds at the side of embryo damages the seed embryo and hence falls to germinate, whereas nicking the seeds at the opposite side of embryo improves seed germination. The statistical test for A. alpina and O. abyssinica seeds also showed that there was a highly statistical significant difference $\left(F_{(0.001)}=45.725\right.$ and $240.562, \mathrm{df}=5$ and 4 , and $P=$ 0.000 ) among treatments, respectively. Overall, the research output for A. alpina and O. abyssinica seeds indicated that seeds do not require seed treatment for seed germination.

3.4. Germination Rate, Germination Energy, and Germination Value of Seeds. Germination data reported that out of the total 100 A. alpina and O. abyssinica sowed seeds in the laboratory, the germination capacity was 73 and $98 \%$, respectively. Their coefficients of rate of germination were 10.7 and 20.9\%, in their respective order. Coefficient of rate of germination is a measure of vigour of seed, and hence germination percentage. Thus, low germination rate means low germination percentage and low vigour of seed. This, in turn, has strong impact on

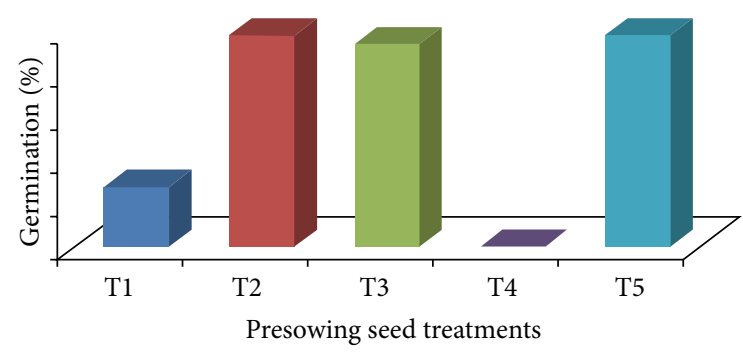

Figure 2: Presowing seed treatments of $O$. abyssinica seeds.

viable seedling production and seedling growth rate as well as morphological appearance [15].

Germination of A. alpina seeds was started on the 7th day and completed on the 17th day. All germinated seeds were recorded within the energy period of 17 days. No germinated seeds were recorded all in all after 17 days of sowing. However, out of the total 28 days of germination period (4 weeks), the germination time was almost uniform within the 1st and 3rd weeks among all the treatments (T1-T6). Germination of $O$. abyssinica seeds, in turn, was completed from the 4th to the 9th day, which lasted for 5 days.

The mean daily germination or daily germination speed of A. alpina and O. abyssinica seeds was 4.29 and $10.89 \%$, respectively. During the entire 28 energy period of the test, their respective peak value (maximum mean daily germination) 6.63 and $18.2 \%$ reached at the 8th and 5th day, in their respective order. Oxytenanthera abyssinica seeds had higher germination energy (98\%) than A. alpina (72\%) within 9 days of energy period. As a result, the percentage of total germinated seeds within the energy period, that is, 16 and 9 days was $98.6 \%$ (A. alpina) and $100 \%$ (O. abyssinica). FAO [12] defined germination energy as the number of germinated seeds in a given sample within a given period, that is, energy period under optimum conditions. It is a measure of the speed of germination and hence the vigour of the seed and the seedlings it produces. Seeds which germinate rapidly and vigorously under favourable conditions of the laboratory are likely to be capable of producing vigorous seedlings, whereas weak or delayed germination is often fatal. Therefore, seeds with shorter germination period have greater germination energy [12]. In line with this, O. abyssinica seeds (85.95) had higher germination value than A. alpina (19.86). This suggests an indication of better seed quality and high vigour of $O$. abyssinica seeds. This, in turn, contributes to better survival rate and well-adapted seedlings in the field $[12,23]$.

\subsection{Effect of Storage Time on A. alpina Seeds Germination} Capacity. Germination of A. alpina seeds was $73,59,66$, and $30 \%$ for $0,180,300$, and 360 days storage, respectively (Figure 3). Freshly collected seeds (0 storage days) had the highest germination, while seeds stored after 360 days had the least. The statistical test similarly reported highly significant differences $\left(F_{(0.001)}=29.443, \mathrm{df}=3\right.$, and $\left.P=0.000\right)$ among the treatments of different storage times. The total mean value was $51.06 \pm 11.69 \%$. This indicated that storage time had a negative impact on seed germination. Similar earlier 


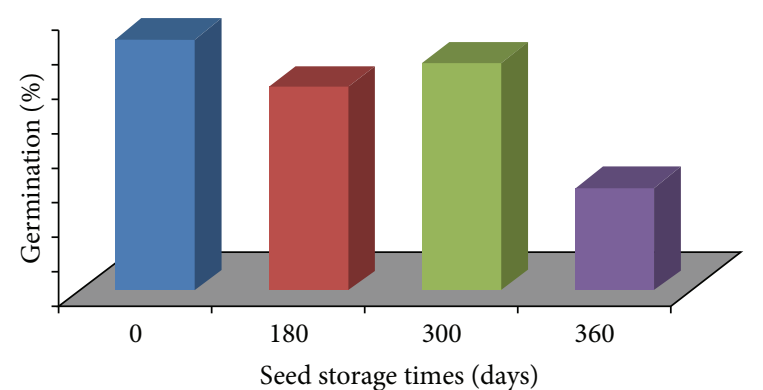

FIgURE 3: Effect of different storage times on A. alpina seeds germination capacity.

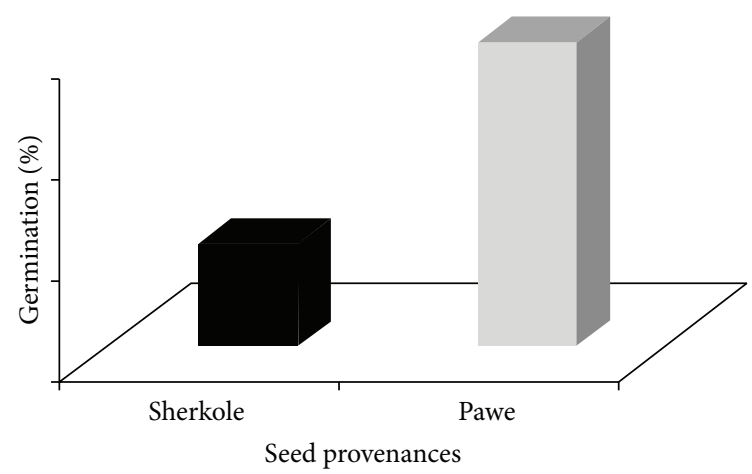

FIGURE 4: Effect of provenances on O. abyssinica seed germination.

finding was reported by Ayana et al. [24]. As the seed storage time increased, there is a gradual decrease in seed viability and/or an increase in seed dormancy in some bamboo species [14]. This showed that seed viability and vigour become gradually declined with increase in storage times. Similar finding was reported by Teketay [25]. Thus, seed storage time has a significant impact on seed germination. However, to conclude the storage behavior of $A$. alpina seeds, the seeds should be further stored at $+5^{\circ} \mathrm{C}$ or lower temperature in cold room and the germination test will be carried out. On the other hand, the orthodox seed storage behavior of $O$. abyssinica seeds was reported by Bahru et al. [21].

3.6. Effect of Provenances on O. abyssinica Seed Germination. The results of $O$. abyssinica seeds germination in the laboratory indicated that Pawe provenance (98\%) had slightly higher germination percentage than Sherkole provenance (97\%) (Figure 4). However, both provenances had the potential in producing viable seeds. The statistical test also showed that there was no significant difference $F_{(0.05)}=0.053$, $\mathrm{df}=1$, and $P=0.826$ ) between the provenances. The total mean value was $83.62 \pm 7.01 \%$. Therefore, seeds from both provenances will be recommended for raising seedlings in the laboratory and transplanting to the nursery.

3.7. Dry Heat Treatment. The experimental result on $O$. abyssinica seeds showed that there was a highly statistical significant difference $\left(F_{(0.05)}=4.515\right.$ and 6.623, $P=0.018$ and 0.004 ) among temperature and duration treatments on

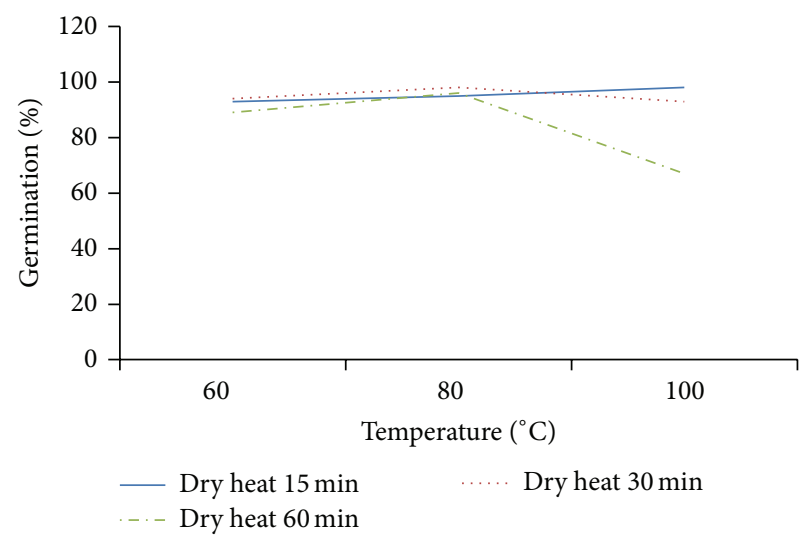

FIGURE 5: Effect of dry heat treatment on O. abyssinica seed germination.

seed germination, respectively. The highest dry heat treatment mean value was $85.89 \pm 8.22 \%$ at $100^{\circ} \mathrm{C}$ for 15 minutes. This was followed by $84.23 \pm 6.66 \%$ at $80^{\circ} \mathrm{C}$ for 30 minutes and the control experiment, whereas the least dry heat mean value of $55.25 \pm 8.17 \%$ was recorded at $100^{\circ} \mathrm{C}$ for 60 minutes. Except seeds treated at $100^{\circ} \mathrm{C}$ for 60 minutes, the rest had significantly higher and uniform germination (93-98\%). This figure was partially reported by earlier studies of Teketay [20]. Overall, the germination percentage of $O$. abyssinica seeds was steeply increased from 60 to $80^{\circ} \mathrm{C}$ and declined to $100^{\circ} \mathrm{C}$ with increasing time (Figure 5). C. C. Baskin and J. M. Baskin [14] reported that dry heat at temperatures of $60-100^{\circ} \mathrm{C}$ causes seeds of many species to become permeable to water. This revealed that appropriate dry heat treatments trigger the germination of $O$. abyssinica seeds. Therefore, heat generated from forest fire in dryland areas acts as one of the factors stimulating seed germination. This is because dry heat caused seed coats of some species to develop cracks and permeable to water thereby promoting the germination of seeds $[14,18]$. According to Martin et al. [18] and C. C. Baskin and J. M. Baskin [14] dry heat treatment is the most effective method in breaking physical dormancy in seeds of a number of species. As the temperature increases, there is a decrease in the length of time to break seed dormancy in most species. For instance, only a few minutes of exposure to temperatures of $\geq 100^{\circ} \mathrm{C}$ are required to break physical dormancy [14]. This result was also similarly reported by earlier studies of Teketay $[19,20]$ and Eshete et al. [26]. In the same way, heat generated from forest fire in dryland areas causes the regeneration of various plant species. This is because it acts as one of the factors stimulating seed germination by breaking the physical dormancy of seeds buried in the soil $[14,18]$. Furthermore, dry heat treatment significantly increased germination more than moist heat in O. abyssinica seeds. But, this result totally disagrees with earlier studies of Martin et al. [18] and Teketay [19, 20].

3.8. Moist Heat Treatment. In moist heat treatments, the highest germination percentage was recorded $(98 \%)$ at $60^{\circ} \mathrm{C}$ for 30 minutes and the least germination $(0 \%)$ was at $100^{\circ} \mathrm{C}$ for 60 minutes. According to Martin et al. [18] moist heat exposure for $4 \mathrm{~min}$ in the range of $90^{\circ} \mathrm{C}-110^{\circ} \mathrm{C}$ appears to 


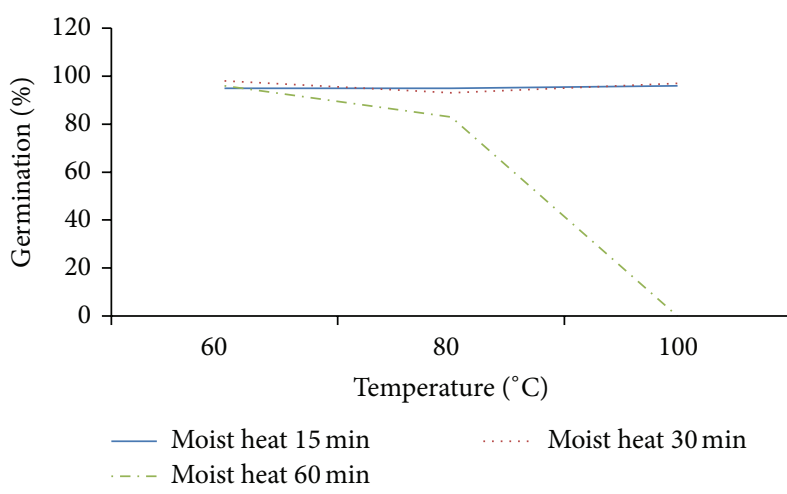

Figure 6: Effect of moist heat treatment on O. abyssinica seed germination.

be lethal to all seed tested. The statistical test using GLM indicated a highly significant difference $\left(F_{(0.01)}=6.446\right.$ and $10.478, P=0.004$ and 0.000 ) among temperature and duration treatments, respectively. The highest moist heat treatment mean value was $84.23 \pm 6.66 \%$ at $60^{\circ} \mathrm{C}$ for 30 minutes and for control. Except seeds treated at $100^{\circ} \mathrm{C}$ for 60 minutes, the rest had significantly higher and uniform germination (83-98\%). But, exposure of seeds to $100^{\circ} \mathrm{C}$ for 60 minutes was lethal ( $0 \%$ germination), suggesting that they are highly sensitive to very high temperature. These seeds were highly infected by seed borne pathogens three to seven days after sowing and decomposed eventually. Seed borne pathogens either reduce germination capability of seeds or cause the failure of germination through weakening or death of embryos [27]. In general, the germination percentage of O. abyssinica seeds was increased from 60 to $80^{\circ} \mathrm{C}$ but declined to $100^{\circ} \mathrm{C}$ with increasing time (Figure 6). This showed that appropriate moist heat treatments break seed dormancy and trigger the germination of $O$. abyssinica seeds. Therefore, moisture generated from forest fire in dryland areas serves as a favourable environmental condition to break seed dormancy and stimulate seed germination as also reported by Martin et al. [18], Teketay [19, 20], and C. C. Baskin and J. M. Baskin [14].

3.9. Light or Dark Treatment. Effect of light or darkness on germination of A. alpina seeds indicated that the dark treatment showed a significantly higher germination percentage $(72 \%)$ than the light treatment $(59 \%)$. The result suggests that there are seeds of some species insensitive to light and hence capable of germinating in darkness even buried in the soil [14]. This is because light can prevent the germination of negatively photoblastic (light inhibited) seeds [14]. Consequently, light is not a limiting factor for the germination of these seeds [25]. On the contrary, light treatment of $O$. abyssinica seeds had slightly higher germination percentage (98\%) than the dark treatment (97\%). Teketay [20] reported that although reasonably high germination can be recorded from dark treated seed, light is necessary to get nearly complete germination. Hence, nondormant seeds of some species do not germinate in darkness or in the absence of light at any temperature. This means they have an absolute light requirement for seed germination [14]. The statistical test of one-way ANOVA showed that there was a significant difference $\left(F_{(0.05)}=8.620\right.$, df $=1$, and $\left.P=0.026\right)$ between light and dark treatments for A. alpina seeds, but no significant difference $\left(F_{(0.05)}=0.053, \mathrm{df}=1\right.$, and $\left.P=0.826\right)$ for $O$. abyssinica seeds. Their total mean values were $54.18 \pm$ $5.52 \%$ and $83.62 \pm 7.01 \%$ for A. alpina and O. abyssinica seeds, respectively. This clearly showed that light is significant for the complete or high germination of $O$. abyssinica seeds as also reported in earlier study by Teketay $[19,25]$.

\section{Conclusion and Recommendation}

Overall, the present study for A. alpina and O. abyssinica seeds indicated that seeds do not require appropriate presowing seed treatments. Control seeds had the best germination, that is, 73 and $98 \%$ for A. alpina and O. abyssinica seeds, respectively. Effect of provenance on O. abyssinica seed germination further revealed that Pawe provenance (98\%) had slightly higher germination than Sherkole provenance (97\%). However, both provenances had the potential in producing viable seeds, which indicates their potential as a seed source. There are 59,416 and 8,393 seeds contained within $1 \mathrm{~kg}$ of $A$. alpina and O. abyssinica seeds within 86 and $91 \%$ pure seeds, respectively. Hence, from $1 \mathrm{~kg}$ of pure seeds 37,301 and 7,168 seedlings are raised in the laboratory in their respective orders. Germination of both dry and moist heat treatments of $O$. abyssinica seeds was significantly improved at 60 and $80^{\circ} \mathrm{C}$ but declined gradually to $100^{\circ} \mathrm{C}$ with time. Unlike $A$. alpina seeds, seeds of $O$. abyssinica had better germination for light treatment compared to dark. Effect of light or darkness on germination of A. alpina seeds indicated that the dark treatment showed a significantly higher germination (72\%) than the light treatment (59\%). On the contrary, light treatment of $O$. abyssinica seeds had slightly higher germination (98\%) than the dark treatment (97\%). In general, for the large scale raising and plantation of A. alpina and O. abyssinica seedlings from its seeds in the laboratory, untreated/control seeds supply to necessary light source (for O. abyssinica seeds) should be recommended.

\section{Conflict of Interests}

The authors declare that there is no conflict of interests regarding the publication of this paper.

\section{Acknowledgments}

The authors are grateful to CEE-FRC/EEFRI, for the financial support and provision of necessary logistic facilities for the entire work. Sincere thanks also go to Assosa and Pawe Agricultural Research Centers as well as Mr. Tesfaye Hunde for collecting and provision of seeds. They are also greatly indebted to seed processing room, tree seed laboratory, nursery, and cold room staffs for their invaluable contribution during the experiment as well as others which directly or indirectly offered their support. 


\section{References}

[1] S. Phillips, "Poaceae (Gramineae)," in Flora of Ethiopia Volume 7, National Herbarium, I. Hedberg and S. Edwards, Eds., pp. 3-6, Biology Department, Science Faculty, Addis Ababa University, Addis Ababa, Ethiopia; Department of Systematic Botany, Uppsala University, Uppsala, Sweden, 1995.

[2] K. Embaye, "The indigenous Bamboo forests of Ethiopia: an overview," Ambio, vol. 29, no. 8, pp. 518-521, 2000.

[3] UNIDO, Bamboo Cultivation Manual. Guidelines for Cultivating Ethiopian Highland Bamboo, Eastern Africa Bamboo Project, United Nations Industrial Development Organization (UNIDO), 2009.

[4] W. Kelecha, The Bamboo Potential of Ethiopia, Forestry and Wildlife Conservation and Development Authority, Addis Ababa, Ethiopia, 1980.

[5] UNIDO, Bamboo Cultivation Manual. Guidelines for Cultivating Ethiopian Lowland Bamboo, Eastern Africa Bamboo Project, United Nations Industrial Development Organization (UNIDO), 2009.

[6] S. Nune, "Short notes on bamboo," in Kosso, A Quarterly Newsletter of the Ethiopian Foresters' Association, pp. 2-5, Ethiopian Foresters' Association (EFA), Addis Ababa, Ethiopia, 2001.

[7] K. Embaye, "Potential of Ethiopian bamboo forests in biodiversity conservation, environment improvement and socioeconomic development," in Conservation of Genetic Resources of Non-Timber Forest Products in Ethiopia. Proceedings of the First National Workshop on Non-Timber Forest Products in Ethiopia, 5-6 April 2004, W. Tadesse and M. Mbogga, Eds., pp. 65-72, EARO/FRC and IPGRI, Addis Ababa, Ethiopia, 2004.

[8] S. Kelemwork, "Bamboo forests of Ethiopia," in Forest Types in Ethiopia: Satus, Potential Contribution and Challenges, K. Kelbessa and A. Girma, Eds., Occasional Report no. 7, pp. 4152, Forum for Environment (FfE), Addis Ababa, Ethiopia, 2011.

[9] Y. G. Assaye, Y. Selassie, and B. Ayele, "A socio-economic contribution of high land bamboo (Yushania Alpina) for household livelihood in Banja District, Northwestern Ethiopia," Journal of Agriculture and Biodiversity Research, vol. 2, pp. 151-159, 2013.

[10] D. Sertse, T. Disasa, K. Bekele et al., "Mass flowering and death of bamboo: a potential threat to biodiversity and livelihoods in Ethiopia," Journal of Biodiversity and Environmental Sciences, vol. 1, pp. 16-25, 2011.

[11] B. N. Kigomo, Guidelines for Growing Bamboo, KEFRI Guideline Series: No. 4, Kenya Forestry Research Institute (KEFRI). Downtown Printing Works, Nairobi, Kenya, 2007.

[12] FAO, "A guide to forest seed handling with special reference to the tropics," FAO Forestry Paper 20/2, Danida Forest Seed Centre, Copenhagen, Denmark, 1985.

[13] FAO, Forest Genetic Resources Information. No. 4. Forest Occasional Paper (1975/1), Food and Agriculture Organization, Rome, Italy, 1975.

[14] C. C. Baskin and J. M. Baskin, Seeds: Ecology, Biogeography and Evolution of Dormancy and Germination, School of Biological Sciences, University of Kentucky, Lexington, Ky, USA; Academic Press, New York, NY, USA, 2001.

[15] H. T. Hartmann and D. E. Kester, Plant Propagation: Principles and Practices, Prentice-Hall International, Upper Saddle River, NJ, USA, 4th edition, 1983.

[16] N. Mamo, M. Mihretu, M. Fekadu, M. Tigabu, and D. Teketay, "Variation in seed and germination characteristics among
Juniperus procera populations in Ethiopia," Forest Ecology and Management, vol. 225, no. 1-3, pp. 320-327, 2006.

[17] T. Bahru, A. Eshete, Y. Mulatu et al., "Effect of provenances on seed germination, early survival and growth performance of Tamarindus indica L. in Ethiopia: a key multipurpose species," Advances in Materials Science and Engineering, vol. 1, no. 1, pp. $1-8,2014$.

[18] R. E. Martin, R. L. Miller, and C. T. Cushwa, "Germination response of legume seeds subjected to moist and dry heat," Ecology, vol. 56, no. 6, pp. 1441-1445, 1975.

[19] D. Teketay, "Germination ecology of twelve indigenous and eight exotic multipurpose leguminous species from Ethiopia," Forest Ecology and Management, vol. 80, no. 1-3, pp. 209-223, 1996.

[20] D. Teketay, "Germination ecology of Acacia negrii, an endemic multipurpose tree from Ethiopia," Tropical Ecology, vol. 38, no. 1, pp. 39-46, 1997.

[21] T. Bahru, B. Kidane, A. Araya et al., "Effects of germination sites on germination percentage, germination energy and germination value of the lowland bambooseeds," in Forestry and Forest Products in Ethiopia: Proceedings of the National Workshop on forestry Research Technologies Dissemination 29-31 May 2012, Hiruy Hall, W. Tadesse, G. Desalign, and A. Yirgu, Eds., pp. 8595, Ethiopian Institute of Agricultural Research (EIAR), Addis Ababa, Ethiopia, 2012.

[22] K. A. Gomez and A. A. Gomez, Statistical Procedures for Agricultural Research, John Wiley \& Sons, New York, NY, USA, 2nd edition, 1984.

[23] L. Ghosh and L. Singh, "Variation in seed and seedling characters of Jatropha curcas L. with varying zones and provenances," Tropical Ecology, vol. 52, no. 1, pp. 113-122, 2011.

[24] D. A. Ayana, Z. Tadesse, and Y. Kebede, "Effect of storage media and storage time on germination and field emergence of Oxytenanthera abyssinica seeds," International Journal of Basic and Applied Sciences, vol. 1, pp. 218-226, 2012.

[25] D. Teketay, "Germination ecology of two endemic multipurpose species of Erythrina from Ethiopia," Forest Ecology and Management, vol. 65, no. 2-3, pp. 81-87, 1994.

[26] A. Eshete, D. Teketay, M. Lemenih, and F. Bongers, "Effects of resin tapping and tree size on the purity, germination and storage behavior of Boswellia papyrifera (Del.) Hochst. Seeds from Metema District, northwestern Ethiopia," Forest Ecology and Management, vol. 269, pp. 31-36, 2012.

[27] D. K. Jha, A Text Book on Seed Pathology, Vikas publishing House Pvt, New Delhi, India, 1995. 

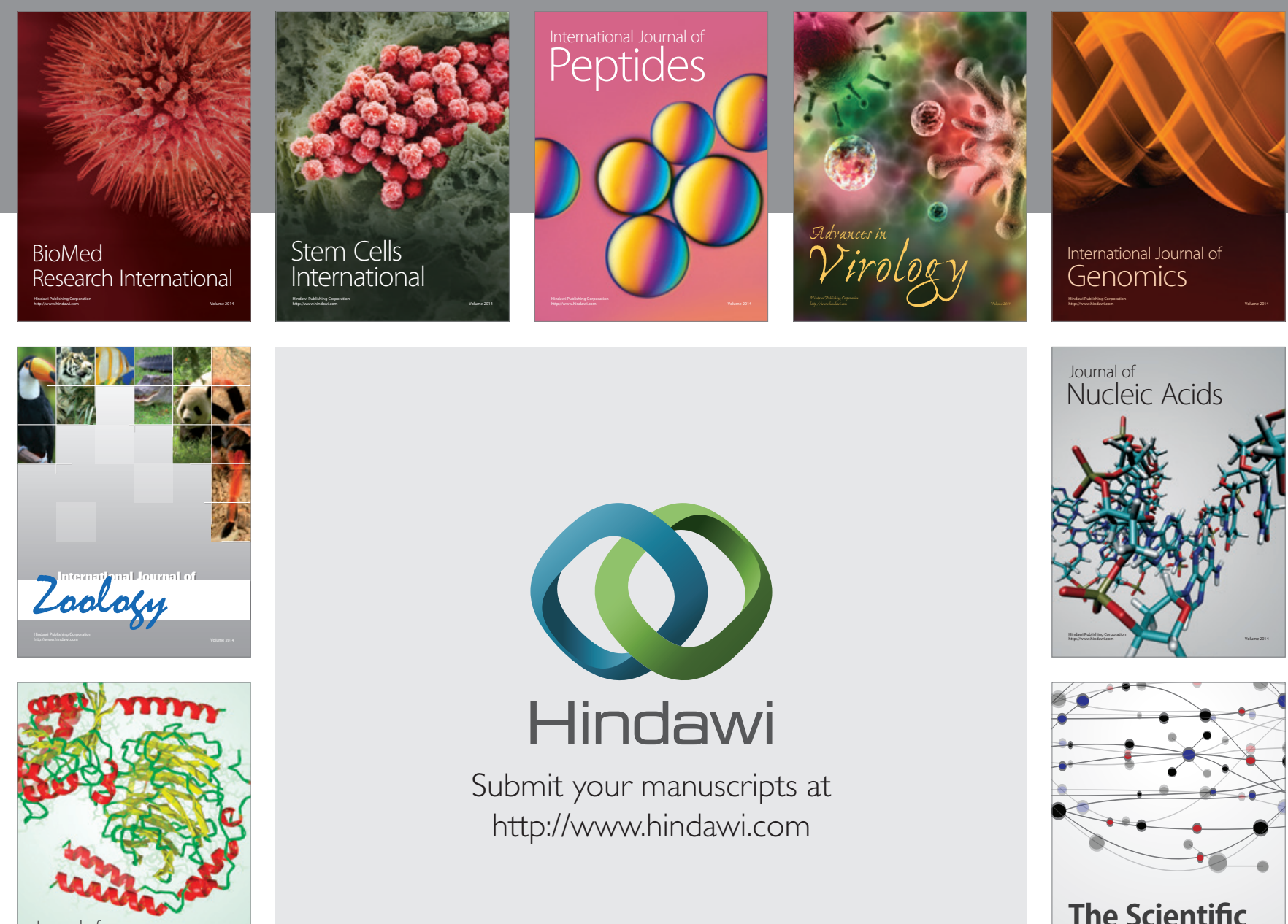

Submit your manuscripts at

http://www.hindawi.com

Journal of
Signal Transduction
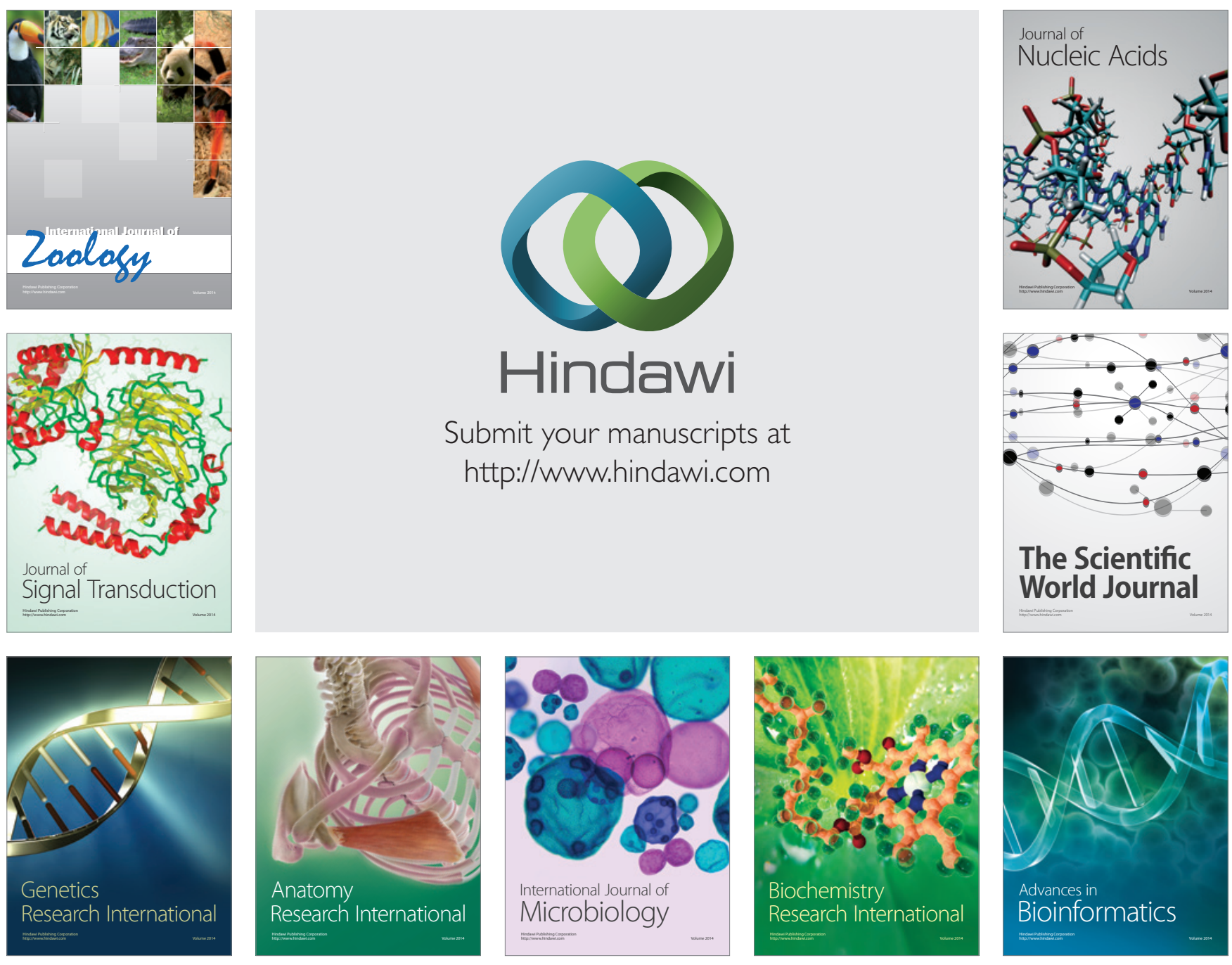

The Scientific World Journal
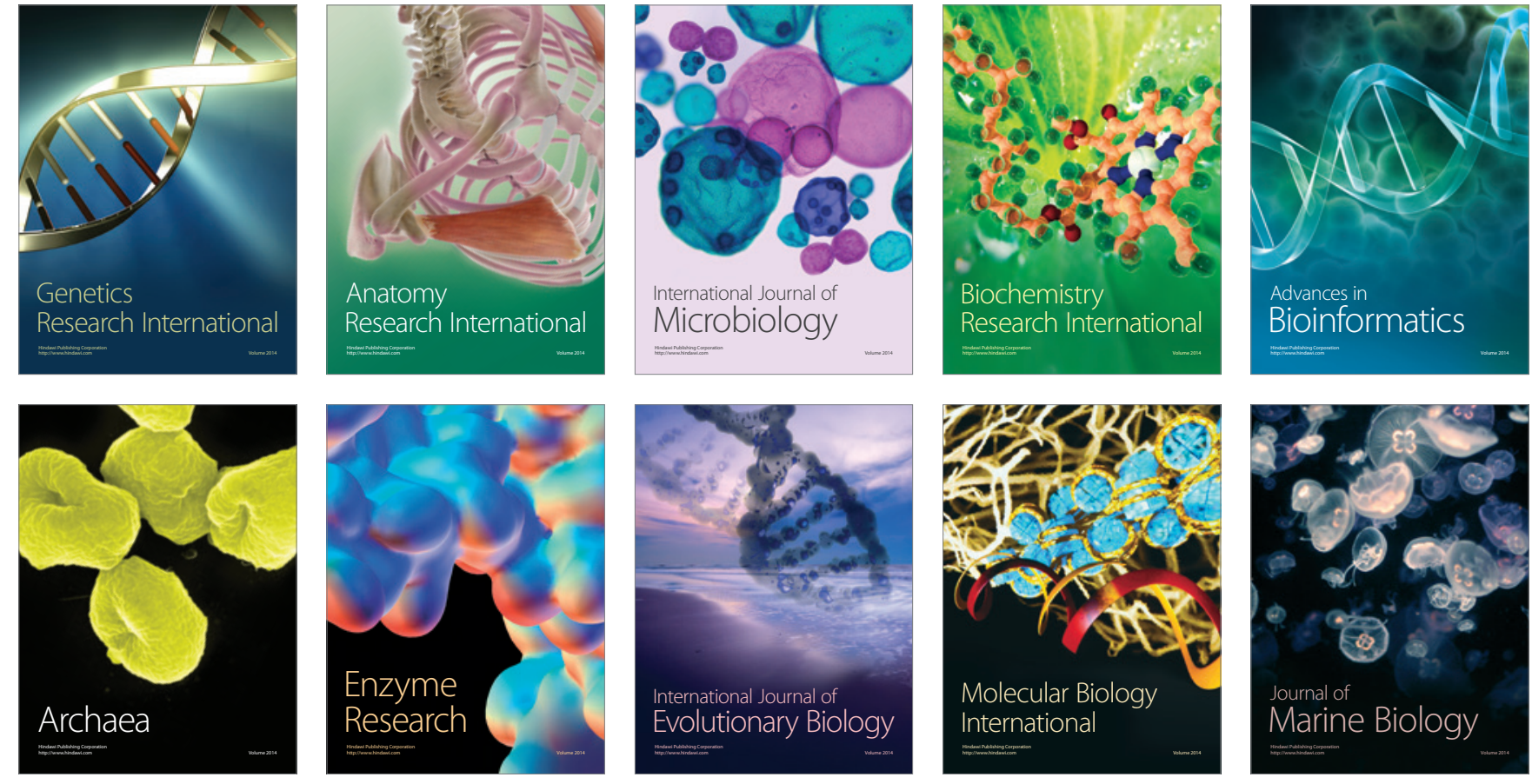